\title{
EFICÁCIA DO FOSFATO DE LEVAMISOL EM NEMATÓDEOS GASTRINTESTINAIS DE CAPRINOS E OVINOS
}

\author{
Lew Kan Sprenger ${ }^{1}$, Carlos Henrique do Amaral' ${ }^{1}$, Ronaldo Viana Leite Filho ${ }^{1}$, \\ Thiago Noleto Aguiar ${ }^{1}$, Marcelo Beltrão Molento ${ }^{1}$
}

\author{
1 UFPR \\ Correspondência: Marcelo Molento: molento@ufpr.br
}

\begin{abstract}
RESUMO: O parasitismo gastrintestinal é considerado o principal entrave na produção de pequenos ruminantes e a ocorrência de parasitos resistentes aos anti-helmínticos tem dificultado seu controle. O objetivo deste trabalho foi avaliar a sensibilidade de nematóides gastrintestinais ao levamisol, em rebanho ovino e caprino criados simultaneamente. Foram utilizados 28 caprinos da raça Bôer e 28 ovinos da raça Texel, naturalmente infectados. Ambas as espécies foram divididas em quatro grupos de sete animais: T1) tratados com $9 \mathrm{mg} / \mathrm{kg}$ de fosfato de LEV; T2) $6,75 \mathrm{mg} / \mathrm{kg}$; T3) $4,5 \mathrm{mg} / \mathrm{kg}$ e T4) grupo controle, sem tratamento. Os animais foram avaliados durante 21 dias para a contagem de ovos por grama de fezes - OPG, coloração da mucosa ocular com o método FAMACHA, hematócrito e peso corporal. Nos ovinos, T1 e T2 foram considerados altamente eficazes (>95\%) e o T3 obteve $86 \%$, que é a dose terapêutica recomendada para ovinos. O LEV não tem indicação oficial para ser utilizado em caprinos e apresentou redução da OPG de 30,11 e 4\%, 14 dias após tratamento, comprovando sua ineficácia. As correlações entre os parâmetros avaliados nos ovinos, foram significativas $(\mathrm{P}<0,01)$, exceto $\mathrm{FAMACHA}$ e peso corporal. No caso dos caprinos, a correlação FAMACHA e hematócrito também não foi significativa. $O$ principal parasito identificado nas coproculturas das duas espécies, realizadas antes e após os tratamentos foi Haemonchus contortus (>84\%). Conclui-se que o LEV foi eficaz para ovinos, sendo dose-dependente. O LEV não pode ser considerado como um composto eficaz no controle de parasitos gastrintestinais em caprinos, possivelmente decorrente de alterações na cinética do produto por esta espécie animal quando comparado com ovinos, devendo ser desencorajado o seu uso.
\end{abstract}

Palavras-chave: caprinos; ovinos; parasitas gastrintestinais

\section{EFFECTIVENESS OF PHOSPHATE LEVAMISOLE IN GASTROINTESTINAL NEMATODES OF GOATS AND SHEEP}

\begin{abstract}
Gastrointestinal parasitism is considered the main obstacle in the production of small ruminants and the occurrence of parasites resistant to anthelmintics has delayed their control. The aim of this study was to evaluate the sensitivity of gastrointestinal nematodes to levamisole (LEV) in sheep and goat simultaneous-raised herds. We used 28 naturally infected Boer goats and 28 Texel sheep. Both species were divided into four groups of seven animals: T1) treated with $9 \mathrm{mg} / \mathrm{kg}$ of LEV phosphate, T2) $6.75 \mathrm{mg} / \mathrm{kg}$; T3) $4.5 \mathrm{mg} / \mathrm{kg}$ and T4) control group, not treated. The animals were evaluated for 21 days for faecal egg count per gram of feces - EPG, color of the conjunctiva with the FAMACHA method, hematocrit and body weight. In sheep, the T1 and T2 were considered highly effective (> 95\%) and T3 was $86 \%$, which is the recommended therapeutic dose for sheep. The LEV has no official indication to be used in goats and showed a decreased on the EPG by 30,11 and $4 \%$, 14 days after treatment, demonstrating its ineffectiveness. The correlations between the parameters evaluated in sheep, were significant $(\mathrm{P}<0.01)$, except FAMACHA and body weight. In the case of goats, hematocrit and FAMACHA the correlation was also not significant. The main parasite identified in stool cultures of the two species, taken before and after treatments was Haemonchus contortus (> $84 \%$ ). It is concluded that the LEV was dose-dependent effective in sheep. LEV cannot be considered as an effective compound in the control of gastrointestinal parasites in goats, possibly due to changes in the drug kinetics when compared to sheep and its usage should be discouraged.

Key Words: gastrointestinal parasites, goats, sheep
\end{abstract}




\section{INTRODUÇÃO}

A criação de pequenos ruminantes no Brasil vem crescendo a cada ano, caracterizando-se como uma alternativa econômica para pequenos e médios produtores. A produção de carne ovina e caprina, em 2011, foi estimada em 78 mil e 42 mil toneladas, respectivamente, apresentando um crescimento de 68 e $247 \%$ nesta ordem, na última década (FAO, 2011). Contudo, predomina no país o modelo de produção com baixos índices produtivos, que advêm da precária nutrição e principalmente do ineficaz manejo sanitário (Gouveia et al., 2009; Almeida et al., 2010).

O parasitismo gastrintestinal é um dos fatores que fragilizam esse tipo de exploração, sendo responsável por perdas econômicas decorrentes do crescimento retardado, perda de peso, diminuição da ingestão de alimentos, redução na produção e baixa fertilidade (Vieira, 2003). Além disso, nos casos de infecção maciça têm-se altas taxas de mortalidade (Molento, 2004a). Desta forma, é necessário conhecer a epidemiologia das espécies que acometem a criação para então adotar estratégias eficazes de controle (Ahid et al., 2008).

O controle das parasitoses em pequenos ruminantes é geralmente realizado com o uso de anti-helmínticos pertencentes a várias classes químicas (benzimidazóis, imidotiazóis, pirimidinas, lactonas macrocíclicas), muitas vezes sem considerar os fatores epidemiológicos predominantes no local (Falbo et al., 2009). Contudo a utilização de modo supressivo e indiscriminado dos antihelmínticos, aliada às falhas de manejo, contribuíram para a seleção de helmintos resistentes aos produtos. A resistência parasitária é um fenômeno pelo qual uma droga não consegue manter a mesma eficácia frente aos parasitas, quando usada nas mesmas condições, após certo tempo (Conder et al., 1995). Devido ao efeito seletivo, a eficácia de qualquer produto antiparasitário pode diminuir bruscamente, favorecendo a permanência da população resistente e a eliminação de indivíduos susceptíveis (Molento, 2005). Entre os fármacos que ainda se apresentam relativamente efetivos está o levamisole, LEV (Vieira et al., 2009; Lima et al., 2010).

O LEV pertence à classe dos imidotiazóis e possui espectro de ação sobre estágios adultos da maioria dos nematódeos gastrintestinais de ruminantes (Lanusse, 1996; Martin e Robertson, 2007). Tanto a absorção quanto a excreção são rápidas, sendo que a ultima ocorre $41 \%$ pelas fezes, $40 \%$ via urina e aproximadamente $2 \%$ na respiração, contudo os resíduos teciduais da droga não são eliminados (Rodrigues et al., 2005). Seu mecanismo de ação se baseia na ação sobre os receptores nicotínicos de acetilcolina (nAChR) dos nematóides, interrompendo a transmissão neuromuscular deixando os parasitos paralisados (Rang et al., 2003).

A eficácia do LEV em ruminantes não é alterada, independente de sua apresentação, como bolus, líquido oral, pellet, injetável ou na forma pour-on como via de aplicação (Reinemeyer e Courtney, 2003). Os tratamentos realizados em caprinos, mesmo fora da recomendação, utilizam doses recomendadas para a espécie ovina ou ainda extrapolando-se a dosagem indicada aos bovinos (Hoste et al., 2010). Coles et al. (1989) sugeriram que as cabras devessem ser tratadas com LEV com uma dose $50 \%$ maior (9 $\mathrm{mg} / \mathrm{kg}$ ) quando comparada a ovinos.

O LEV é pouco seguro, apresentando pequena margem de segurança devido ao seu baixo índice terapêutico (Andrade e Santarém, 2002). Sabe-se que o produto apresenta toxicidade para espécies animais como cavalos, cães e gatos (Almeida e Aires, 
2006). Contudo devido ao baixo nível de segurança, o mesmo é potencialmente nocivo à todos os mamíferos (Adams, 2003). Mesmo sendo indicado como antiparasitário para ovinos, o risco de ocorrer uma intoxicação é preocupante (Andrade e Santarém, 2002). Esse perigo é mais alarmante no caso dos caprinos, pois requer doses maiores que as preconizadas para outros ruminantes, não se sabendo ao certo qual a dose efetiva para esta espécie. Sugere-se que seja devido a uma menor taxa de metabolização hepática (Hoste et al., 2010; Lespine et al., 2011), causando sinais de intoxicação (sialorréia, hiperestesia, irritabilidade, excitação, depressão do sistema nervoso central, dispnéia, defecação e micção involuntárias) (Allen et al., 2005).

Coles (2005) enfatizou que existem diversas drogas disponíveis para ovinos, entretanto são raras as que foram testadas frente aos nematóides gastrintestinais de caprinos e nenhum estudo comprovou sua aplicabilidade no Brasil. O objetivo deste trabalho foi avaliar a sensibilidade dos nematóides gastrintestinais ao LEV, em rebanho caprino e ovino.

\section{MATERIAL E MÉTODOS}

Local do experimento - O
experimento foi realizado em uma
propriedade no município de Balsa
Nova, PR, que esta localizado a 2535'02" S 49³8'09" N com clima subtropical úmido $\mathrm{Cfb}$, pela classificação de Köppen. Foi utilizado um rebanho ovino e outro caprino com manejo semelhante, sendo que os animais não receberam tratamento anti-helmíntico no período de 90 dias que antes do estudo.

Animais experimentais - Foram utilizados 28 caprinos da raça Bôer e 28 ovinos da raça Texel, de ambos os sexos, com faixas etárias variando entre quatro a seis meses de idade, peso corporal entre 16 e $26 \mathrm{~kg}$ e naturalmente infectados por nematódeos gastrintestinais. Os critérios adotados para a seleção dos animais incluídos neste experimento foram: diagnóstico positivo para parasitos gastrintestinais pela contagem do número de ovos por grama de fezes, OPG, superior a 300; animais saudáveis ao exame clínico geral e pelo método FAMACHA (van Wyk et al., 2002).

Os animais foram marcados individualmente por meio de brincos, sendo aleatoriamente distribuídos em quatro grupos de sete animais cada e abrigados em aprisco suspenso, que foi higienizado diariamente. Os grupos foram formados de forma aleatória, respeitando a homogeneidade de OPG, idade, peso e sexo. Os animais foram alimentados com forragem de capim quicuio (Pennisetum clandestinum) e suplementação de $9 \%$ de proteína, além de receber água ad libitum.

Tratamento - Foi utilizado o LEV via oral. Os animais foram submetidos a um jejum alimentar de 12 horas antes da administração do medicamento. Foram utilizados quatro tratamentos: T1) animais tratados com $9,0 \mathrm{mg} / \mathrm{kg}$, que é uma concentração $50 \%$ superior a dose recomendada para ovinos e é a dose recomendada informalmente para caprinos; T2) dose de $6,75 \mathrm{mg} / \mathrm{kg}$ (recomendada para ovinos); T3) dose de $4,5 \mathrm{mg} / \mathrm{kg}$ (concentração $50 \%$ menor que a dose recomendada para ovinos); T4) grupo controle, sem tratamento.

Coleta de amostras e exame FAMACHA - Amostras de fezes foram colhidas diretamente da ampola retal de cada animal, identificadas em sacos plásticos e mantidas sob refrigeração até o processamento da OPG e para a obtenção das larvas por meio de coprocultura. As coletas foram feitas nos dias: $-3,0,7,14$ e 21. No dia 0 foi realizado 0 tratamento com 0 antiparasitário. Foi coletado $5 \mathrm{ml}$ de sangue da veia jugular externa, de cada indivíduo, por meio de tubos BD 
vacutainer com o uso de anticoagulante (EDTA) para analise de hematócrito, nas mesmas datas que as coletas de fezes.

O método FAMACHA foi realizado em todos os animais e em todos os dias em que houve coleta de fezes. O exame foi realizado em um local com luz natural, classificando a coloração da conjuntiva com auxílio do cartão FAMACHA. Esse guia segue os parâmetros estabelecidos por van Wyk et al. (2002) alocando os animais em cinco categorias, que vão desde 0 vermelho forte (grau 1), até o branco pálido (grau 5) em animais gravemente anêmicos. Os caprinos foram avaliados seguindo indicação de Molento et al. (2004a). Os animais foram pesados no início (Dia 0) e ao término (Dia 21) do experimento.

Exames laboratoriais - A contagem de OPG foi realizada pela técnica descrita por Gordon \& Whitlock (1939). Foram realizados exames individuais de fezes de todos os indivíduos nos cinco dias em que foram coletas amostras. Para coprocultura, foram utilizadas amostras apenas do dia 0 e do dia 21 . As coproculturas foram realizadas em pool, misturando amostras fecais somente dos animais de cada grupo experimental, seguindo-se a metodologia de Roberts \& O'Sullivan (1950) e para identificação de 100 larvas utilizou-se a chave de Keith (1953). A mensuração do percentual de células sanguíneas foi efetuada pelo método do microhematócrito (Jain, 1993). Já para a determinação das proteínas plasmáticas totais (PPT) se seguiu o protocolo preconizado por Wolf et al. (1962).

Análises dos dados - Foram calculadas as médias aritméticas da OPG de cada grupo tratado (OPGt) e comparadas com as médias do grupo controle (OPGc) para se obter a eficácia de cada tratamento, baseada na fórmula descrita por COLES et al. (2006):
Eficácia = (1- [OPGt/OPGc] $) \times 100$

Foram obedecidas as instruções da World Association for the Advancement of Veterinary Parasitology (COLES et al., 1992), onde a resistência é detectada quando o percentual de redução no teste de redução da contagem de ovos nas fezes (TRCOF) for menor que $95 \%$ e o limite inferior do intervalo de confiança estiver abaixo de $90 \%$.

Os dados obtidos foram analisados pelo software estatístico GraphPad Prism 5, realizando analise de variância e comparando as médias pelo teste de Scott-Knott, a 5\% de significância. Os dados de OPG, FAMACHA, VG e peso corporal, de cada espécie animal, foram submetidos à análise de correlação. As frequências dos gêneros de nematódeos foram comparadas pelo Teste de Qui-Quadrado, ao nível de significância de 5\%. Essas duas análises foram realizadas utilizando 0 software estatístico anteriormente citado.

\section{RESULTADOS E DISCUSSÃO}

Ovinos - Ovinos do grupo T1 e T2 apresentaram diferença $(P<0,05)$ em relação à redução no TRCOF quando comparados aos animais do grupo T3 e T4 em todas as amostragens após o tratamento. O mesmo ocorreu com o grupo T3 em comparação ao grupo T4. Não foi observada diferença estatística $(P>0,05)$ entre os animais dos grupos T1 e T2 durante o experimento (Tabela 1). Foi observada redução acima de 95\% em T1 e T2 em todas as análises. Logo, com os critérios estabelecidos pela WAAVP, os dois protocolos foram considerados eficazes. Muito embora o tratamento utilizado no grupo T3 não tenha sido considerado eficaz (<95\%), possivelmente decorrente da presença de parasitos resistentes e selecionados ao longo dos anos. Entretanto se pode considerar uma eficácia acima de $80 \%$ 
como sendo eficaz quando obtida após teste de campo, e que poderá assegurar a manutenção da saúde animal devido a disseminação de parasitos resistentes (Niciura et al., 2012).

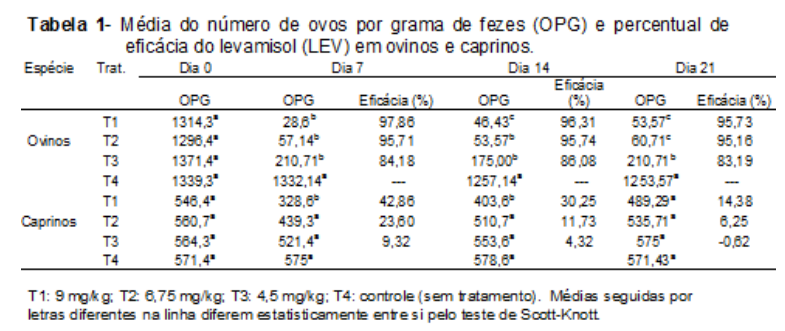

Os dados encontrados corroboram com os resultados apresentados por Ramos et al. (2002), Duarte et al. (2010) e Lima et al. (2010) que relataram a eficácia anti-helmíntica do LEV em ovinos, no estado do Santa Catarina, São Paulo e Pernambuco, respectivamente. Contudo não existem trabalhos citando os efeitos da subdosagem utilizada no grupo T3. Traversa e Molento et al. (2012) relataram que o uso de $50 \%$ da dose terapêutica de ivermectina alcançou $82 \%$ de eficácia em equinos, semelhante ao resultado do LEV em ovinos.

No dia 0, após a obtenção de larvas $L_{3}$, os gêneros identificados foram, Haemonchus, Trichostrongylus, Oesophagostomun e Strongyloides spp. (Tabela 2). O gênero Haemonchus sp. é - principal parasita que atinge a produção de ovinos, seguido do Trichostrongylus sp. (Amarante et al., 2004). Esses também são os principais parasitas encontrados na Região Sul do Brasil (Thomaz-Soccol et al., 2004; Rosalinski-Moraes et al., 2007).

\begin{tabular}{|c|c|c|c|c|c|c|c|c|c|}
\hline \multirow[t]{2}{*}{ Espécie } & \multirow[t]{2}{*}{ Tratamento } & \multirow{2}{*}{\multicolumn{4}{|c|}{ (96) Dis 0}} & \multicolumn{4}{|c|}{ (96) Dia 21} \\
\hline & & Haem. & & Oeso. & Stron. & Hsem. & Trich. & Oeso. & Stron. \\
\hline & T1 & 82 & 17 & 0 & 1 & 95 & 5 & 0 & 0 \\
\hline \multirow[t]{4}{*}{ Ovinos } & T2 & 77 & 20 & 3 & 0 & 96 & 4 & 0 & 0 \\
\hline & T3 & 80 & 18 & 1 & 1 & 98 & 2 & 0 & 0 \\
\hline & T4 & 84 & 13 & 2 & 1 & 85 & 11 & 2 & 2 \\
\hline & $\mathrm{T} 1$ & 77 & 14 & 0 & 9 & 96 & 4 & 0 & 0 \\
\hline \multirow{3}{*}{ Caprinos } & T2 & 76 & 15 & 2 & 7 & 93 & 7 & 0 & 0 \\
\hline & T3 & 73 & 21 & 2 & 4 & 90 & 10 & 0 & 0 \\
\hline & $\mathrm{T}_{4}$ & 82 & 15 & 0 & 3 & 84 & 12 & 0 & 4 \\
\hline
\end{tabular}

Entretanto, no dia 21, somente Haemonchus e Trichostrongylus spp. foram encontrados na coprocultura, mostrando que estes dois gêneros foram resistentes ao uso do LEV nas três dosagens utilizadas. A resistência desses parasitas ao LEV em ovinos foi primeiramente observada no Rio Grande do Sul (Santiago et al., 1979). Desde então muitos trabalhos vêm mostrando a predominância do parasitismo por Haemonchus sp. e Trichostrongylus sp. em rebanhos de ovinos tratados com LEV (Fernandes et al., 2004; Ramos et al., 2004; Depner et al., 2007; Rosalinski-Moraes et al., 2007; Pereira et al., 2008; SczesnyMoraes et al., 2010; Duarte et al., 2012), como também determinado neste trabalho.

Os resultados deste estudo permitem evidenciar que, tanto em ovinos quanto em caprinos, o Haemonchus contortus foi a espécie de maior prevalência e que apresentou 0 mais elevado índice de resistência frente ao LEV.

Em relação ao método FAMACHA (Tabela 3), para os ovinos de todos os grupos no dia -3 , foi observado uma maior frequência do grau $4(60,7 \%)$, seguido do $3(32,1 \%)$, e 2 (7,2\%). Nas visualizações após a realização do tratamento, observou-se que nos grupos T1, T2 e T3, houve moda para o grau 1. Nesse caso predominou o valor $1(95,2 \%)$, seguido de $2(4,8 \%)$. Para o T4 o grau $4(76,6 \%)$ e $3(23,4 \%)$ foram respectivamente os mais encontrados. O uso desse método além de permitir uma significativa diminuição na frequência de tratamentos realizados, pode ainda selecionar indivíduos mais tolerantes/resilientes ao H. contortus (Kaplan et al., 2004; Molento et al., 2004b). 


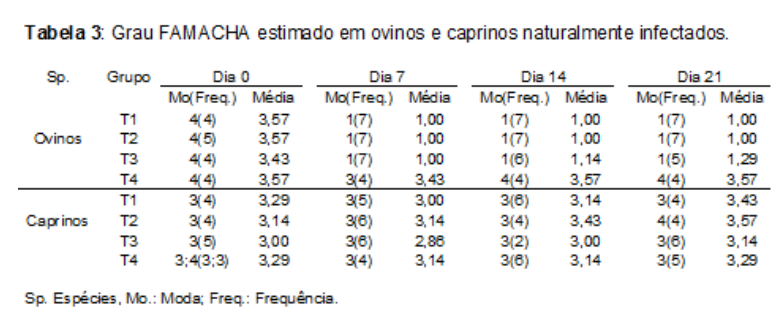

O teste de correlação foi realizado utilizando todos os parâmetros obtidos no estudo: OPG, peso corporal, hematócrito e FAMACHA e correlacionando-os entre si (Tabela 4). Entre as comparações realizadas, apenas FAMACHA e peso corporal não foi considerada significativa $(P>0,01)$. Esses resultados são semelhantes aos realizados por Depner et al. (2007) e Abrão et al. (2010). A alta correlação, inversamente proporcional, entre FAMACHA e OPG é devido a significativa presença de $H$. contortus e esse fato corresponde a alta correlação entre FAMACHA e hematócrito. Assim, o uso de métodos alternativos de diagnóstico possibilitaram assegurar a saúde do rebanho.

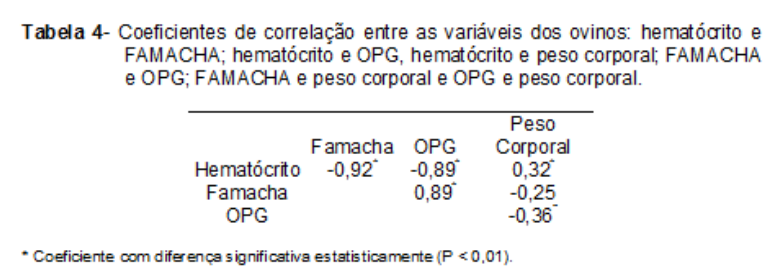

Caprinos - Já nos caprinos, os grupos tratados apresentaram diferença estatística $(P<0,05)$ em relação à TRCOF quando comparados ao grupo controle após o dia 0 . Também houve diferença $(P<0,05)$ dos grupos $T 1, T 2$ e T3 quando os mesmo foram comparados entre si (Tabela 1). Contudo, durante todo o experimento nenhum dos tratamentos aplicados aos caprinos foi considerado eficaz (>95\%).

No dia 0 se identificou os gêneros: Haemonchus, Trichostrongylus, Strongyloides e Oesophagostomun sp. (Tabela 2). De acordo com Costa Junior et al., 2005) esses quatro parasitos estão associados a significativas perdas econômicas devido a grande taxa de mortalidade e atraso no crescimento
(Araújo et al., 2006; Vieira et al., 2008). No dia 21, foram encontrados Haemonchus sp. e Trichostrongylus sp. na coprocultura dos animais que receberam tratamento, resultado este, semelhante a outros, onde foi determinada ineficácia do LEV frente aos nematóides gastrintestinais (Melo et al., 2003; Rodrigues et al., 2007; Lima et al., 2010).

Com relação ao FAMACHA, no dia -3 as maiores frequências obtidas foram: 3, 2 e 4, respectivamente (Tabela 3). As modas nos exames após o tratamento variaram entre os grupos e no mesmo grupo. Para caprinos essa técnica é menos precisa, pois a coloração da conjuntiva ocular dessa espécie tem menos intensidade e o tempo de preenchimento capilar é maior quando comparado com ovinos (Molento et al., 2004a). Logo, existe baixa correlação entre a cor da mucosa ocular e o hematócrito ou peso corporal (van Wyk et al., 1997). O método FAMACHA é uma boa ferramenta quando se visa a implementação de tratamento seletivo (Vilela et al., 2012), porém deve-se realizar estudos aprofundados no assunto para aumentar sua eficiência em caprinos (Molento et al., 2004a; Vilela et al., 2008). O FAMACHA não apresentou correlação significativa $(P>0,01)$ com 0 peso corporal ou com o hematócrito (Tabela 5). Esses resultados corroboram com estudos para esta espécie (KAPLAN et al., 2004; MOLENTO et al., 2004a).

$$
\begin{aligned}
& \text { Tabela 5- Coeficientes de correlação entre as variáveis dos caprinos: hematócrito } \times \\
& \text { FAMACHA; hematócrito e OPG; hematócrito e peso corporal; FAMACHA } \\
& \text { E OPG; FAMACHA e peso corporal e OPG e peso corporal. }
\end{aligned}
$$

\begin{tabular}{cccc}
\hline & & & Peso \\
& Famacha & OPG & Corporal \\
Hematócrito & $-0,72$ & $-0,3^{-}$ & 0,18 \\
Famacha & & $0,39^{-}$ & $-0,19$ \\
OPG & & & $-0,3^{-}$
\end{tabular}

As cabras são menos eficientes do que ovelhas na aquisição e expressão de resposta imune contra nematóides gastrintestinais (Hoste et al., 2008). Este fato pode ser devido a uma menor taxa de metabolização e excreção dos anti- 
helmínticos nos caprinos quando comparado com os ovinos (Lespine et al., 2011). A atividade metabólica hepática, principalmente oxidação e hidroxilação é maior em cabras do que em ovelhas, com isso as concentrações plasmáticas de anti-helmínticos nas cabras decrescem em uma maior velocidade (McKenna et al., 1987). Além disso, o reflexo da ranhura esofágica é mais proeminente nesses animais do que em ovelhas e, portanto, pode influenciar na absorção do medicamento (Sangster et al., 1991).

Para alguns autores, a falta de eficácia do LEV em caprinos ocorra somente devido a resistência dos nematódeos gastrintestinais a estes animais (Vieira et al., 1997; Barreto et al., 2002; Melo et al., 2003). Contudo, os resultados do presente trabalho sugerem a possibilidade de que a dose terapêutica utilizada para ovinos (T2) e a dose recomendada para caprinos (T1) possam atuar como sub-dose quando administrada em caprinos. Sendo assim esses tratamentos não somente seriam ineficazes, como manteriam uma alta carga parasitária nos animais, prejudicando seu rendimento e bem estar.

Apesar de não haver estudos tratando diretamente desse assunto, a literatura existente reforça a opinião de que cabras requerem doses específicas e não extrapolações de recomendações feitas à outras espécies de ruminantes (Jackson et al. 2012). Logo a realização desse trabalho é um importante marco inicial para os estudos a cerca da dosagem correta de LEV em caprinos, ou mesmo da recomendação de seu não-uso nesta espécie.

Existe ainda a preocupação quanto a administração de doses superiores as recomendadas na terapêutica oficial em caprinos com o objetivo de sanar a carência de estudos apropriados. Desta forma, é importante enfatizar a utilização de doses elevadas e que podem causar grave intoxicação aos animais, acarretando prejuízo à saúde animal.

\section{CONCLUSÃO}

Concluiu-se que o LEV foi ineficaz no controle de parasitos gastrintestinais de caprinos em todas as dosagens testadas, apresentando resistência na dose terapêutica em ovinos. $O$ FAMACHA mostrou-se uma prática útil para o diagnóstico de parasitoses em ovinos. Contudo em caprinos, o mesmo deve ser usado juntamente a outra ferramenta diagnóstica, tendo em vista a baixa correlação encontrada. $H$. contortus foi a espécie mais prevalente antes e após os tratamentos.

\section{REFERÊNCIAS}

ABRAO, D.C.; ABRAO, S.; VIANA, C.H.C.; et al. [2010]. Utilização do método

FAMACHA no diagnostico clinico individual de haemoncose em ovinos no sudoeste do Estado de Minas Gerais. Revista Brasileira de Parasitologia Veterinária, v.19, n.1,p.70-72, 2010

ADAMS, H.R. Veterrinary Pharmacology and Therapeutic, 8.ed. Arnes: Wiley-Blackwell, 2001. p 955.

AHID, S.M.M.; SUASSUNA, A.C.D.; MAIA, M.B.; et al. [2008]. Parasitos gastrintestinais em caprinos e ovinos da região Oeste do Rio Grande do Norte, Brasil. Ciência Animal Brasileira, v.9, n.1, p.212218, 2008.

ALLEN, D.G.; DOWLING, P.M.; SMITH, D.A. Handbook of veterinary drugs. 3.ed.

Philadelphia: Lippincott Williams \& Wilkins, 2005. $1111 \mathrm{p}$.

ALMEIDA, L.R.; CASTRO, A.A.; SILVA, F.J.; et al. [2005]. Desenvolvimento, sobrevivência e distribuição de nematóides gastrintestinais de ruminantes, na estação seca da Baixada Fluminense, RJ. Revista Brasileira de Parasitologia Veterinária, v.14, n.3, p 89-94, 2005.

ALMEIDA, A.C.; TEIXEIRA, L.M.; DUARTE, E. R.; et al. [2010]. Perfil sanitário dos rebanhos caprinos e ovinos no Norte de Minas Gerais. Comunicata Scientiae, v.1, n.2, p.161-166, 2010.

AMARANTE, A.F.T. Controle de endoparasitoses dos ovinos. In: REUNIÃO ANUAL DA SOCIEDADE BRASILEIRA DE ZOOTECNIA, 3., 2001, Piracicaba.

Anais... Piracicaba: Sociedade Brasileira de Zootecnia, 2001. p. 461-471. 
AMARANTE, A.F.T.; BAGNOLA JUNIOR, J.; AMARANTE, M.R.V.; et al. [1997]. Host specificity of sheep and cattle nematodes in São Paulo State, Brazil. Veterinary Parasitology, v.73, n.1-2, p.89104, 1997.

AMARANTE, A.F.T.; BRICARELLO, P.A.; ROCHA, R.A.; et al. [2004] Resistance of Santa Ines, Suffolk and lle de France lambs to naturally acquired gastrointestinal nematode infections. Veterinary Parasitology, v.120, n.1-2, p. 91-106, 2004.

AUBRY, M.; COWELL, P.; DAVEY, M.; et al. [1970]. Aspects of the pharmacology of a new anthelmintic: Pyrantel. Brazilian Journal of Pharmacology, v. 38,p. 332-334, 1970.

ARAÚJO, J.V.; FREITAS, B.W.; VIEIRA, T.C.; et al. [2006]. Avaliação do fungo predador de nematóides Duddingtonia flagrans sobre larvas infectantes de Haemonchus contortus e Strongyloides papillosus de caprinos. Revista Brasileira de Parasitologia Veterinária, v.15, n.2, p.76-79, 2006.

BAKER, K.E.; GEORGE, S.D.; STEIN, P.A.; et al. [2012] Efficacy of monepantel and anthelmintic combinations against multiple-resistant Haemonchus contortus in sheep, including characterisation of the nematode isolate. Veterinary Parasitology, v.186, n.3-4, p. 513-517, 2012.

BARRETO, M.A; ALMEIDA, M.A.O.; SILVA, A.; et al. Eficácia anti-helmíntica do cloridrato de levamisole, albendazole e ivermectin em caprinos, na região Semi-árida da Bahia. In: CONGRESSO BRASILEIRO DE MEDICINA VETERINARIA (CONBRAVET), XXIX, 2002, Gramado. Anais... Gramado:

SBMV/SOVERGS, 2002.

BESIER, B. [2007]. New anthelmintics for livestock: the time is right. Trends in Parasitology, v.23, n.1, p.21-24, 2007.

BUZZULINI, C.; SOBRINHO, A. G. S.; COSTA, A. J.; et al. [2007]. Eficácia anti-helmíntica comparativa da associação albendazole,levamisole e ivermectina à moxidectina em ovinos. Pesquisa Agropecuária Brasileira, v.42, n.6, p.891-895, 2007.

CHARLES, T.P.; POMPEU, J.; MIRANDA, D.B [1989]. Efficacy of three broad-spectrum anthelmintics against gastrointestinal nematode infections of goats. Veterinary Parasitology, v.34, n.1-2, p.71-75, 1989.

COLES, G.C. [2005]. Anthelmintic resistance-looking to the future: a UK perspective. Research in Veterinary Science, v.78, n.2, p.99-108, 2005.

COLES, G.C.; BAUER, C.; BORGSTEEDE, F.H.M.; et al. [1992]. World association for the advancement of veterinary parasitology (WAAVP) methods for the detection of anthelmintic resistance in nematodes of veterinary importance. Veterinary Parasitology, v.44, n.1, p.35-44, 1992.
COLES, G.C.; GIORDANO, D.J.; TRITSCHLER, J.P [1989]. Efficacy of levamisole against immature and mature nematodes in goats with induced infections. American Journal of Veterinary Research, v.50, n.7, p.1074-1075, 1989.

COLES, G. C.; JACKSON, F.; POMROY, W. E.; et al. [2006]. The detection of anthelmintic resistance in nematodes of veterinary importance. Veterinary Parasitology, v.136, n.3-4, p.167-185, 2006.

CONDER, G.A.; CAMPBELL, W.C. [1995] Chemoterapy of nematode infections of veterinary importance, with special reference to drug resistance. Advances in Parasitology, v.35, p.1-83, 1995.

COSTA V.M.M., SIMÕES S.V.D.; RIET-CORREA F. [2009]. Doenças parasitárias em ruminantes no semiárido brasileiro. Pesquisa Veterinária Brasileira, v.9, n.7, p.563-568, 2009.

COSTA JÚNIOR G.S.; MENDONÇA I.V.; CAMPELO J.E.G.; et al. [2005]. Efeito de vermifugação estratégica, com princípio ativo à base de ivermectina na incidência de parasitos gastrintestinais no rebanho caprino da UFPI. Ciência Animal Brasileira, v 6, n.4, p.279-286, 2005.

DEPNER, R.A.; GAVIÃO, A.A.; CECIM, M.; et al. [2007]. Desempenho de cordeiros naturalmente infectados com parasitas gastrintestinais utilizando o tratamento seletivo com o método Famacha e o tratamento preventivo. Archives of Veterinary Science, v.11, n.3, p. 32-37, 2007.

DUARTE, F.C.F.; SILVA, I.C. ESTEVES, A.; et al. [2010]. Eficácia anti-helmíntica de cloridrato de levamisol (7,5\%), via subcutânea, em ovinos do município de Descalvado/SP. Revista Saúde, v. 4, sup. 1, 2010.

DUARTE, E.R.; SILVA, R.B.; VASCONCELOS, V.O.; et al. [2012]. Diagnóstico do controle e perfil de sensibilidade de nematóides de ovinos ao albendazol e ao levamisol no norte de Minas Gerais. Pesquisa Veterinária Brasileira, v.32, n.2, p.147-152, 2012.

FALBO, M.K.; SANDINI, I.E.; ISHIY, H.M.; et al. [2008]. Atividade anti-helmíntica do fruto de Melia azedarach em cordeiros naturalmente infectados com nematódeos gastrintestinais. Semina: Ciências Agrárias. v.29, n.4, p.881-886, 2008.

FERNANDES L.H.; SENO M.C.Z.; AMARANTE A.F.T.; et al. [2004]. Efeito do pastejo rotacionado e alternado com bovinos adultos no controle da verminose em ovelhas. Arquivo Brasileiro de Medicina Veterinária e Zootecnia, v.56, n.6, p.733740,2004

FOOD AND AGRICULTURE ORGANIZATION - FAO. [2011]. FAOSTAT - FAO Statistics Division/ProdSTAT: livestock (primary and processed).

GARCIA-BARATUTE, A.; MORALES, G.; RAMÓN SOTTO, V. ; et al. [2007]. Efecto de la edad de crías 
ovinas Pelibuey en pastoreo continuo sobre la infestación por estrongílidos gastrointestinales, ganancia de peso y mortalidad. Zootecnia Tropical, v. 25, n.3, p.167-172, 2007.

GEORGI, J.R.; GEORGI, M.E. Parasitology for veterinarians. Philadelphia: W.B. Saunders, 1990. $412 p$.

GORDON, H.M.; WHITLOCK, H.V. [1939]. A new technique for counting nematode eggs in sheep faeces. Journal of the Council for Scientific and Industrial Research, v.12, p.50-52, 1939.

GOUVEIA, A.M.G.; GUIMARÃES, A.S.; HADDAD,J.P.A.; et al. [2009]. Características zoosanitárias da ovinocultura em Minas Gerais. In: Associação dos Criadores de Caprinos e Ovinos de Minas Gerais, 2009.

HOSTE, H.; SOTIRAKI, S.; LANDAU, S.; et al. [2010] Goat-Nematode interactions: think differently. Trends in Parasitology, v.26, n.8, p.376- 381, 2010.

HOSTE, H.; TORRES-ACOSTA, J.F.J.; AGUILAR CABALLERO,A.J. [2008]. Nutrition-parasite interactions in goats: is immunoregulation involved in the control of gastrointestinal nematodes? Parasite Immunology, v.30, n.2, p.79-88, 2008.

JACKSON, F.; VARADY, M.; BARTLEY, D.J. [2012]. Managing anthelmintic resistance in goats-Can we learn lessons from Sheep? Small Ruminant

Research, v.103, n.1, p.3-9, 2012.

JAIN, N.C. Essencials of veterinary

hematology. Philadelphia: Lea \& Febiger, 1993, p.417.

KAPLAN, R. M.; BURKE, J.M.; TERRILL, T.H.; et al. [2004]. Validation of the Famacha eye color chart for detecting clinical anemia in sheep and goats on farms in the southern United States. Veterinary

Parasitology, v.123, n. 1-2, p.105-120, 2004.

KEITH, R. K. [1953]. The differential of the infective larval of some common nematode parasites of cattle. Australian Journal of Zoology, v.2, p. 223-230, 1953.

KOPP, S.R.; COLEMAN, G.T.; TRAUB, R.J.; et al. [2009]. Acetylcholine receptor subunit genes from Ancylostoma caninum: altered transcription patterns associated with pyrantel resistance. International Journal for Parasitology, 2009;39:435-41.

LANUSSE, C.E. Farmacologia dos compostos antihelmínticos. In : CHARLES, T. P. Controle de nematóides gastrintestinais em ruminantes. Juiz de Fora: Terezinha Padilha, 1996. p.1-44.

LESPINE, A.; CHARTIER, C.; HOSTE, H. et al. [2012] Endectocides in goats: Pharmacology, efficacy and use conditions in the context of anthelminticsresistance. Small Ruminant Research, v.103, n.1, p.10-17, 2012.
LIMA, W.C.; ATHAYDE, A.C.R.; MEDEIROS, G.R. et al. [2010]. Nematóides resistentes a alguns antihelmínticos em rebanhos caprinos no Cariri Paraibano. Pesquisa Veterinária Brasileira. v.30, n.12, p.1003-1009, 2010.

MALAN F.S.; VAN WYK J.A. The packed cell volume and colour of the conjunctivae as aids for monitoring Haemonchus contortus infestations in sheep, In: ANONYMOUS, PROCEEDINGS OF THE SOUTH AFRICAN VETERINARY ASSOCIATION BIENNIAL NATIONAL VETERINARY CONGRESS, 1992, Grahamstown, Anais..., 1992, p. 139.

MÁRQUEZ LARA, D. Resistencia a los antihelmínticos: origen, desarrollo y control. Revista Corpoica, v.4, n.1, p.55-71, 2003.

MARTIN, R.J.; ROBERTSON, A.P. [2007]. Mode of action of levamisole and pyrantel, anthelmintic resistance, E153 and Q57. Parasitology, v 134, p.93-104, 2007.

MCKENNA, P.B.; WATSON, T.G. [1987]. The comparative efficacy of four broad-spectrum anthelmintics against some experimentally induced trichostrongylid infections in sheep and goats. New Zealand Veterinary Journal, v.35, n.11, p.192-195, 1987.

MELO A.C.F.L.; REIS I.F.; BEVILAQUA C.M.L.; et al. [2003]. Nematódeos resistentes a anti-helmínticos em rebanhos de ovinos e caprinos do estado do Ceará, Brasil. Ciência Rural, v.33, n.2, p. 339-344, 2003.

MOLENTO M.B. 2004a. Resistência de helmintos em ovinos e caprinos. XIII Congresso Brasileiro de Parasitologia Veterinária e I Simpósio LatinoAmericano de Ricketsioses, Ouro Preto, Minas Gerais. Revista Brasileira de Parasitologia Veterinária, v.13, sup. 1, p.82-87.

MOLENTO, M.B. Resistência parasitaria em helmintos de equídeos e propostas de manejo. Ciência Rural, v.35, n.6, p.1469-1477,2003.

MOLENTO, M.B.; GAVIÃO, A.A.; DEPNER, R.A.; et al. Frequency of treatment and production performance using the FAMACHA method compared with preventive control in ewes. Veterinary Parasitology, v.162, p.314-319, 2009.

MOLENTO, M.B.; TASCA, C.; GALLO, A.K., et al. Método FAMACHA como parâmetro clínico individual de infecção por Haemonchus contortus em pequenos ruminantes. Ciência Rural, v.34, n.4, p.1139-1145, 2004b.

MORTENSEN, L.L.; WILLIAMSON, L.H.; TERRILL, T.H.; et al. [2003]. Evaluation of prevalence and clinical implications of anthelmintic resistance in gastrointestinal nematodes in goats. Journal American of the Veterinary Medicine Associantion, v.223, n.4, p.495-500, 2003.

PEREIRA R.C.F.; TOSCAN G.; VOGEL F.S.F.; et al. Resistência de helmintos gastrointestinais em ovinos 
Eficácia do fosfato de levamisol em nematódeos gastrintestinais de caprinos e ovinos

de Rosário do Sul, RS, Brasil. In: CONGRESSO BRASILEIRO DE MEDICINA VETERINÁRIA, XXXV, 2008, Gramado. Anais... Gramado: Sociedade Gaúcha de Veterinária, 2008. CD-ROM.

PRICHARD, R.K.; HALL, C.A.; KELLY, J.D.; et al. [1980]. The problem of anthelmintic resistance in nematodes. Australian Veterinary Journal, v. 56, n.5, p.239-251, 1980.

RAMOS, C. I.; BELLATO, V.; DE ÁVILA, V. S.; et al. [2002]. Resistência de parasitos gastrintestinais de ovinos a alguns anti-helmínticos no Estado de Santa Catarina, Brasil. Ciência Rural, v.32, n.3, p.473-477, 2002.

RAMOS C.L.; BELLATO V.; SOUZA A.P.; et al. [2004]. Epidemiologia das helmintoses gastrintestinais de ovinos no Planalto Catarinense. Ciência Rural, v.34, n.6, p.1889-1895, 2004.

REINEMEYER, C.R.; COURTNEY, C.H.

Quimioterapia da Doença Parasitária. In: ADAMS, H.

$R$. Farmacologia e terapeutica em Veterinária. 8.ed. Rio de Janeiro: Guanabara Koogan, 2003, Cap. 10, p. $792-818$.

ROBERTS, F.H.S.; O'SULLIVAN, J.P. Methods of egg counts and larval culturesfor strongyles infesting the gastrointestinal tract of cattle. Australian Agriculture Research, v.1, p.99-102, 1950.

RODRIGUES A.B.; ATHAYDE A.C.R.; RODRIGUES O.G.; et al. Sensibilidade dos nematóides gastrintestinais de caprinos a anti-helmínticos na mesorregião do Sertão Paraibano. Pesquisa Veterinária Brasileira, v.27, n.4, p.162-166, 2007.

RODRIGUES, O.G.; SOUSA, M.R.Q.; DUARTE, M.H.S.; et al. [2005]. Avaliação da Influência de Levamisole sobre Padrões de Proteínas e Leucograma em Caprinos (Capra hircus) Nativos da Região Semi-Arida Nordestina. Agropecuária Científica no Semi-árido, v.1,n.1, p.50-58, 2005.

ROSALINSKI-MORAES F.; MORETTO L.H.; BRESOLIN W.S.; et al. Resistência antihelmíntica em rebanhos ovinos da região da Associação dos Municípios do Alto Irani (AMAI), Oeste de Santa Catarina. Ciência Animal Brasileira, v.8, n.3, p.559565, 2007.

RUAS, J.L.; BERNE, M.E.A. Parasitoses por nematódeos gastrintestinais em bovinos e ovinos. In: Correa F.R.; Schild A.L.; Mendez M. del C.; et al. Doenças de Ruminantes e Equinos. v.2, 2. ed., São Paulo: Varela, 2001, p.19-162.

SANGSTER, N.C.; RILEY, F.L.; WILEY, L.J. [1998]. Binding of [H-3]m-aminolevamisole to receptors in levamisole-susceptible and -resistant Haemonchus contortus. International Journal for Parasitology, v.28, n.5, p.707-717, 1998.

SANGSTER, N.C.; SONG, J.; DEMELER, J. [2005] Resistance as a tool for discovering and understanding targets in parasite neuromusculature. Parasitology, v.131(Suppl.), p179-90, 2005.

SANTIAGO, M.; COSTA, U. C.; BENEVENGA, S. Atividade anti-helmíntica de dl-tetramisole e do thiabendazole em uma estirpe de Trichostrongylus colubriformis resistente ao levamisole. Revista Centro Ciências Rurais, v.8, n.3, p.257-261, 1978.

SANTOS, V.T.; GONÇALVES, P.C. Verificação de estirpes resistentes de Haemonchus contortus resistente ao thiabendazole no Rio Grande do Sul (Brasil). Revista da Faculdade de Agronomia e Veterinária, v.9, p.201-209, 1967.

SCZESNY-MORAES, E.A.; BIANCHIN, I.; DA SILVA, K.F. et al. [2010]. Resistência anti-helmíntica de nematóides gastrintestinais em ovinos, Mato Grosso do Sul. Pesquisa Veterinária Brasileira, v.30, n.3, p 229-236, 2010.

SILVA, W. W.; BEVILAQUA, C. M.; ROCRIGUES, M. L. A. Variação Sazonal de Nematóides Gastrintestinais em Caprinos Traçadores no SemiÁrido Paraibano-Brasil. Revista Brasileira de Parasitogia Veterinária, v.12, n.2, p.71-75, 2003.

SPINOSA, H. S.; GÓRNIAK, S. L.; BERNARDI, M. M. Farmacologia aplicada à medicina veterinária. 2. ed. Rio de Janeiro: Guanabara Koogan, 2002. 646p.

TRAVERSA, D.; MOLENTO, M. Drug resistance in horse cyathostomins in South America and Europe. XVIII Congresso Internacional de Medicina Tropical e Malaria. Rio de Janeiro. CD-Rom, 198p, 2012.

THOMAZ-SOCCOL, V.; SOUZA, F.P.; SOTOMAIOR, C.; et al. [2004]. Resistance of gastrointestinal nematodes of anthelmintics in sheep (Ovies aries). Brazilian Archives of Biology and Technology, v.47, n.1, p.41-47, 2004.

WALLER, P. J. [1997]. Anthelmintic resistance. Veterinary Parasitology, v.72, n.3-4, p.391-412, 1997.

WALLER, P. J.; RYDZIK, A.; LJUNGSTROM, B. L.; et al. [2006]. Towards the eradication of Haemonchus contortus from sheep flocks in Sweden. Veterinary Parasitology,v.136, n.3-4, p.367-372, 2006.

WEBSTER, C.R.L. Farmacologia Clínica em Medicina Veterinária. 1. ed. São Paulo: Roca, 2005. 150 p.

WOLF, A.V.; FULLER, J.B.; GOLDMAN, E.J.; et al. New refractometric methods for determination of total proteins in serum and in urine. Clinical Chemistry, v.8, n.158, p.158-165, 1962.

VAN WYK, J.A.; MALAN, F.S.; BATH, G.F. Rampant anthelmintic resistance in sheep in South Africa what are the options? In: WORKSHOP OF MANAGING ANTHELMINTIC RESISTANCE IN ENDOPARASITES, 1997, Sun City, África do Sul Anais... Sun City, 1997. p.51-63. 
VÁRADY, M.; PAPADOPOULOS, E.; DOLINSKÁ, M.; et al. [2011] Anthelmintic resistance in parasites of small ruminants: sheep versus goats.

Helminthologia, v.48, n.3, p.137-144, 2011.

VIDAL, M.F.; SILVA, R.G.; NEIVA, J.N.M.; et al. [2006]. Análise econômica da produção de ovinos em lotação rotativa em pastagem de capim tanzânia (Panicum maximum (JAcq)). Revista de Economia e Sociologia Rural, v.44, n.4, p.801-818, 2006.

VIEIRA, L.S. Alternativas de controle de verminose gastrintestinal dos pequenos ruminantes. Brasília: EMBRAPA, n.29, p. 1-10, 2003.

VIEIRA L.S. [2008]. Métodos alternativos de controle de nematóides gastrintestinais em caprinos e ovinos. Tecnologia \& Ciência Agropecuária, v.2, n.2, p.4956, 2008.

VIEIRA, L.S.; CAVALCANTE, A.C.R. Resistência antihelmíntica em rebanhos caprinos no Estado do Ceará. Pesquisa Veterinária Brasileira, v.19, n.3-4, p.99-103, 1997.

VIEIRA, L.S.; CAVALCANTE, A.C.R.; XIMENES, L.J.F. Epidemiologia e controle das principais parasitoses de caprinos nas regiões semi-áridas do Nordeste do Brasil. Circular Técnica. Sobral: Embrapa Caprinos, 49p. 1997.

VIEIRA M.I.B.; ROCHA H.C.; RACTZ L.A.B.; et al. Comparação de dois métodos de controle de nematódeos gastrintestinais em borregas e ovelhas de corte. Semina: Ciências Agrárias. v 29, n.4, p. 853-860, 2008.

VILELA, V.L.R.; FEITOSA, T. F.; LINHARES, E. F.; et al. FAMACHA ${ }^{\odot}$ method as an auxiliary strategy in the control of gastrointestinal helminthiasis of dairy goats under semiarid conditions of Northeastern Brazil.

Veterinary Parasitology, s/n, 2012.

VILELA, V.L.R.; SOLANO, G.B.; ARAÚJO, M.M.; ET $A L$. Ensaios preliminares para a validação do Método FAMACHA ${ }^{\odot}$ em condições de semiárido paraibano. Revista Brasileira de Parasitologia Veterinária, v.17, p.164-167, 2008. 